\title{
Timothy Ray Brown: The Serendipitous Hero of HIV Cure Research
}

\author{
Thomas J. Hope, ${ }^{1}$ Nichole R. Klatt, ${ }^{2}$ Jonah B. Sacha, ${ }^{3}$ and Paula M. Cannon ${ }^{4}$
}

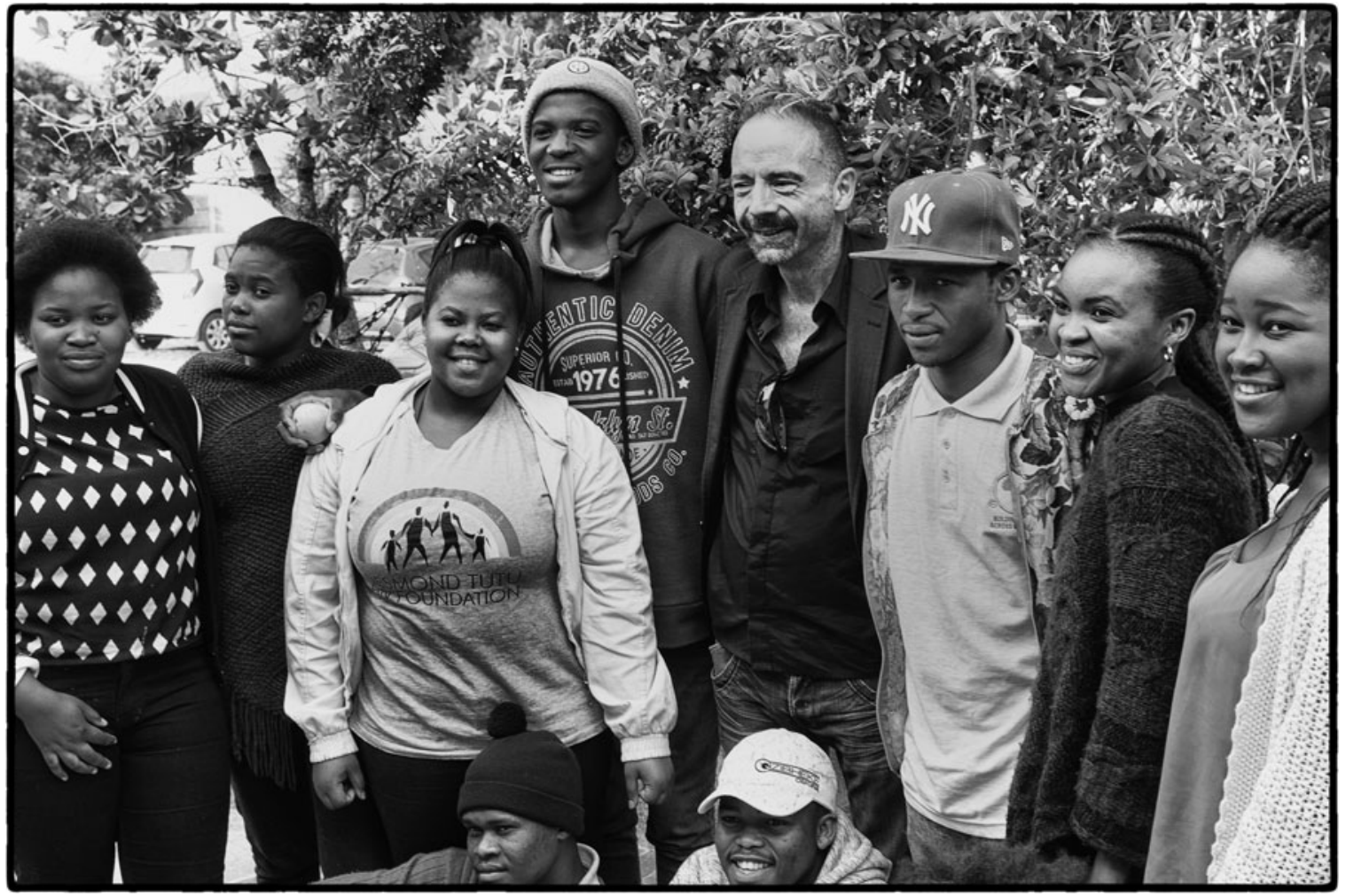

Timothy Ray Brown after a joyous visit to a youth group in Cape Town on September 11, 2017, where he spoke to about 50 young people about cure, his treatment, and taking antiretrovirals (ARVs). Photo credit: Clive Gray, University of Cape Town, South Africa.

Keywords: Timothy Ray Brown, HIV cure, Berlin patient

$\mathbf{I}$ IS WITH GREAT SADNESS that we write about the tragic passing of Timothy Ray Brown, the first person cured of HIV infection. Amidst the chaos of the COVID-19 pandemic, we have lost a treasured voice in the fight against the still ongoing HIV/AIDS pandemic that continues to ravage the world. Timothy Ray Brown, the first person ever cured of HIV infection, died on Tuesday September 29, 2020. His first battle with leukemia over a decade ago was overcome with 2 bone marrow transplants that had led to him becoming the first person cured of HIV infection. Unfortunately, his recent second encounter with leukemia took his life. It was these bone marrow transplants, and the idea of his physician, Dr. Gero Hütter, that led to him being cured. ${ }^{1}$ As previously documented, he was initially not interested in his "cure experiment." But after two rounds of ablation and bone marrow transplants, he was able to stop antiviral therapy without any

\footnotetext{
${ }^{1}$ Department of Cellular and Developmental Biology, Feinberg School of Medicine, Northwestern University, Chicago, Illinois, USA.

${ }^{2}$ Department of Medicine, University of Minnesota, Minneapolis, Minnesota, USA.

${ }^{3}$ Vaccine and Gene Therapy Institute, Oregon Health \& Science University, Beaverton, Oregon, USA

${ }^{4}$ Department of Molecular Microbiology and Immunology, Keck School of Medicine, University of Southern California, Los Angeles, California, USA.
} 
return viremia, which is the text book definition of being cured of HIV.

Given Health Insurance Portability and Accountability Act (HIPPA) rules governing personal medical records, Timothy could have said thank you and moved on with his life. However, he chose a different path to reveal his identity and became a great champion of HIV Cure Research and an ambassador for the importance of science in improving the health of all. Voices such as Timothy's are essential in helping the public to understand the importance and value of science on our general health. This is especially driven home during the current pandemic, which has similarities to the emerging HIV pandemic in terms of fear, confusion, and defiance. Timothy Ray Brown's unfailing voice and activism for HIV research will be missed, as will his care and support of young researchers and future efforts to develop a cure for HIV.

His advocacy is well documented. Here we would like to capture the man, Timothy Ray Brown, and his impact by relating our personal and public experiences with him. Interestingly, the four of us were all independently drawn to work with and support Timothy based on his enthusiasm and dedication to be an ambassador for HIV research. Although we were already friends and collaborators, we were surprised to discover our overlapping efforts through our interactions with Timothy at various meetings and gatherings. By coordinating our efforts in support of Timothy's advocacy he was able to expand his reach and impact around the world through participation in meetings, conferences, workshops, and other activities supporting the effort to develop a cure for HIV. Unfortunately, we could only offer support and encouragement to Timothy as he fought and ultimately lost his second fight with leukemia.

We will miss him as our friend and the world will be lessened by the loss of his unique impact on public awareness of the importance to stay focused of overcoming the AIDS pandemic. Here we hope to share his humanity and eagerness to advance HIV research and his impact on the fight against the AIDS pandemic, so that his advocacy can be remembered by those who never had the chance to meet our friend, Timothy Ray Brown.

\section{Nikki Klatt}

I remember meeting Timothy as a postdoc, and as most, despite his humble shyness, I was in awe of him and his presence could immediately be felt. Timothy was not just an advocate, but he also humanized HIV research, giving hope and motivation to researchers around the world. He made the research not just about samples in a laboratory, but about real people, with real lives. As scientists, it is easy to get bogged down in the laboratory, thinking of experiments and biology, and Timothy made us realize we are not doing this work to get a publication, or the next grant, but to actually help people. He often spoke about how he did not know why he was lucky enough to be cured but he wants others to join him. His earnestness was humbling. Every time I got to see Tim at meetings, I would coordinate a dinner with him and invite other researchers, and most importantly young investigators. It was an honor to watch Tim interact with people in a more casual setting, where he would share when prompted, but more so he spent the evenings asking everyone about themselves, their research, and their lives.
It was not the fact that Tim was cured of HIV that made him so special. It was that he genuinely cared about others, no matter what walk of life they came from, and selflessly gave himself: his body for research, his inspiration, his concern and support, and his name, of which has probably been used thousands of times by researchers investigating an HIV cure. Through the years, I had the great fortune to get to know Timothy not just as an advocate or a symbol as an HIV cure, but as my friend Tim. We shared laughter and tears; talked a little science, but mostly just joked (and cringed) about politics, discussed life issues, and shared stories. It was a great honor that I got to visit him at home on hospice, and hold his hand as he whispered to keep doing research, to send his love to all, and to keep fighting. Tim fought hard and was the strongest person I have ever met. His legacy will continue, and not just for an HIV cure, but for decency, equality, and compassion to all.

\section{Jonah Sacha}

There exist a few moments in my career that stand out in my memory with total clarity, similar to the moment of elation when my PhD thesis committee told me I passed, or absolute terror when on stage for my first public presentation and I was unable to answer a question asked, or the sense of wonder of meeting the inspiration for my research. That last moment happened in July 2015 at the International AIDS Society (IAS) meeting in Vancouver when I finally worked up the nerve to introduce myself to Timothy Brown. I stumbled my way through my introduction and then proceeded to tell him that I was so captivated by his story that I decided to make a complete left turn in my career to begin working on HIV cure through stem cell transplantation in macaques. I expected him to just nod, smile, and slowly walk away, but instead his response was so genuine that I have never forgotten that afternoon moment we shared standing in a sunsoaked hallway in the Vancouver convention center looking at the ships in harbor. He told me he was honored I had started working on cure because of him and he encouraged me to work as diligently and as quickly as I could so that he was not alone in being cured, that he wanted siblings in his cure family. It was such an honest and humble comment, an encapsulation of who he was, and I have never forgotten it.

As the conversation went on, we discovered we had much in common, having both lived in Berlin and learned to speak German there. Over the years subsequent to that first conversation, I am lucky enough to say he went from being not only my inspiration, but also my friend. This year, for spring break, my family had rented a house in Palm Springs and I was excited to finally introduce my three young boys to my friend Timothy so they could know why their dad stays up late most nights to work. Alas, COVID-19 ruined those plans, and although they will never meet him now, they know who Timothy was and why he is so important to the world, to scientists, and to me. The first person cured of HIV could have been anyone, but we were lucky it was him.

It is a shame that the wheels of scientific progress turn slowly and that Timothy will not be here to see the full returns of the sea change he set in motion, that elusive HIV panacea. Outside my office is a bulletin board that I started years ago with only articles about Timothy and the work he inspired. It was a hard moment to hang his obituary. But I was still able to smile for a brief moment standing there because I knew it 
would not be the last time I hung up an article about him. Because of his bravery, because of who he was, because of his willingness to share himself with the world, because of the massive impact he had on me and countless others in the field, professionally and personally, his legacy as a pioneer, as our champion, as my friend will live on.

\section{Paula Cannon}

Timothy was gentle, sweet, mischievous, and a most unlikely hero. Scientists, not usually known for being starstruck, were drawn to his quiet charisma and powerful symbolism. As a gene therapy researcher working on CCR5 disruption, I met Timothy at many HIV Cure meetings where we would sometimes sit on the same panel or end up in the same restaurant. And then somewhere along the line, we simply became just friends. After he and his partner moved to Palm Springs, I got to see him several times a year, where he was always happy to pass on his recommendations for restaurants in Palm Springs. It is hard to accept that the enormity of his HIV cure could not protect him from the return of the cancer. In his final days his life was filled with love and friends and the protection and appreciation of his community. A special man who changed our perception of what is possible and will continue to inspire.

\section{Tom Hope}

I first met Timothy in 2012 at the annual Palm Springs HIV Pathogenesis meeting. He had made a brave decision to become a public figure in 2010 by revealing himself as the Berlin Patient, the first person to be cured of HIV. Attendees were informed that he would speak at the end of the conference. This seemed unusual to me and at first, I stood in the back of the full room. But the palpable buzz in the room inspired me to step forward and grab the last available seat in the front row. Timothy told his story. I was truly moved by a man who had survived two bone marrow transplants with a $50 \%$ survival rate to overcome leukemia, while becoming cured of HIV. What captured my attention was the sincerity of his words and the kindness in his heart. In that presentation, Timothy made it clear that he wanted to advocate for HIV Cure Research. I thought, "this guy is a real person" with an amazing story.

As I heard him tell his story several more times, it became clear that he was to become a special ambassador for all who have been affected by the virus and I decided to do what I could to help him with his important efforts. Here was a person who could have just said thank you for curing me, and moved forward with his life. But instead, often at great personal sacrifice, he decided to do what he could to be a cheerleader for HIV Cure Research. I was lucky to be able to spend quite a bit of time with Timothy at scientific meetings and gatherings around the world. It was especially joyful to see him welcomed like a rock star by young people around the world. I saw young researchers and students in South Africa and Brazil stand in long lines to take a selfie or exchange pleasantries. Timothy patiently greeted all with a big smile and a kind heart.

To support his ongoing advocacy, AIDS Research and Human Retroviruses gave Timothy a voice to tell his own story in four articles. ${ }^{2-5}$ In each, Timothy tells his own story that shines through with honesty and sincerity and true benevolence. Those were his superpowers that made him a bona fide superhero as he traveled around the world. Losing Timothy is a terrible blow to his cause. We must all do what we can to continue to advocate for HIV Cure Research. To keep the support of the public for infectious disease research, it is important that we all carry forward the spirit of Timothy as we endeavor to find a cure for those to whom Tim gave so much and so freely

\section{References}

1. Hutter G, Nowak D, Mossner M, et al:: Long-term control of HIV by CCR5 delta32/delta32 stem-cell transplantation. N Engl J Med 2009;360:692-698.

2. Brown TR: The London patient. AIDS Res Hum Retroviruses 2020;36:251-252.

3. Brown TR: Timothy Ray Brown's continuing activism toward curing HIV. AIDS Res Hum Retroviruses 2018;34: 9-11.

4. Brown TR: Don't let funding caps to NIH researchers harm highly collaborative HIV cure research. AIDS Res Hum Retroviruses 2017;33:iv.

5. Brown TR: I am the Berlin patient: a personal reflection. AIDS Res Hum Retroviruses 2015;31:2-3.

Address correspondence to:

Thomas J. Hope, PhD

Department of Cellular and Developmental Biology

Feinberg School of Medicine

Northwestern University

Simpson Querrey Biomedical Research Center 6th Floor 303 East Superior Avenue Chicago, IL 60611

USA

E-mail: thope@northwestern.edu 